\title{
Intracystic Hematoma of Middle Fossa Arachnoid Cyst Caused by Rupture of Internal Carotid-Posterior Communicating Artery Aneurysm
}

\author{
-Case Report-
}

\author{
Ikki KAJIWARA, Toshihide TANAKA, Issei KAN, Toshihiro OHTSUKA, \\ Satoshi SAWAUCHI, Shigeyuki MURAKAMI, and Toshiaki ABE* \\ Department of Neurosurgery, Jikei University Kashiwa Hospital, Kashiwa, Chiba; \\ ${ }^{*}$ Department of Neurosurgery, Jikei University School of Medicine, Tokyo
}

\begin{abstract}
A 46-year-old woman was admitted with generalized convulsion and deep coma which occurred 3 weeks after sudden onset of severe headache and pyrexia. Initial computed tomography did not reveal any abnormal findings except for an arachnoid cyst in the right middle fossa. Three weeks later repeat computed tomography showed intracystic hematoma in the arachnoid cyst with uncal herniation. Angiography revealed a right internal carotid-posterior communicating artery aneurysm. The neck of the aneurysm was clipped successfully, but hemiparesis was persistent postoperatively. Angiography is required for investigation of intracystic hematoma of an arachnoid cyst, especially in the absence of head injury, to avoid delayed diagnosis of any ruptured aneurysm.
\end{abstract}

Key words: arachnoid cyst, intracystic hematoma, ruptured aneurysm

\section{Introduction}

Arachnoid cyst in the middle cranial fossa is common, and the use of computed tomography (CT) and magnetic resonance imaging has increased the detection rates. ${ }^{1,8)}$ The incidence of arachnoid cyst is approximately $1 \%$ of all intracranial space-occupying lesions. Arachnoid cyst is thought to be congenital in nature, and rarely causes clinical symptoms through the mass effect on neighboring structures. Intracystic hematoma with arachnoid cyst is often associated with subdural hematoma after head trauma. ${ }^{1,7,8)}$ The unsupported blood vessels surrounding arachnoid cyst are most likely to be veins which may bleed spontaneously or after relatively minor head trauma. Consequently, head trauma may result in subdural hematoma or intracystic hemorrhage.

Here we report a case of an arachnoid cyst in the middle fossa with intracystic hematoma caused by rupture of an aneurysm arising from the right internal carotid-posterior communicating artery.

Received July 11, 2007; Accepted January 11, 2008

\section{Case Report}

A 46-year-old woman was admitted to a local hospital with sudden onset of severe headache and pyrexia. CT showed an arachnoid cyst in the right sylvian fissure without mass effect, and no hemorrhage in the basal cistern, sylvian fissure, or convexity sulci (Fig. 1A). The symptoms improved spontaneously. Three weeks after onset, she presented with generalized tonic and clonic seizure, and then fell into deep coma. CT demonstrated intracystic hemorrhage in the arachnoid cyst with uncal herniation (Fig. 1B). Right carotid angiography revealed a right internal carotid-posterior communicating artery aneurysm, with the dome projecting posterolaterally (Fig. 2).

Craniotomy was performed, the cystic wall was opened, and thick hematoma was evacuated. No subarachnoid hemorrhage was found. The dome of the aneurysm with bleb protruded into the cystic wall, which avoided occlusion of posterior communicating artery. The neck of the aneurysm was detected on opening of the cystic wall. The aneurysm neck was clipped with three titanium clips. The patency of the posterior communicating 

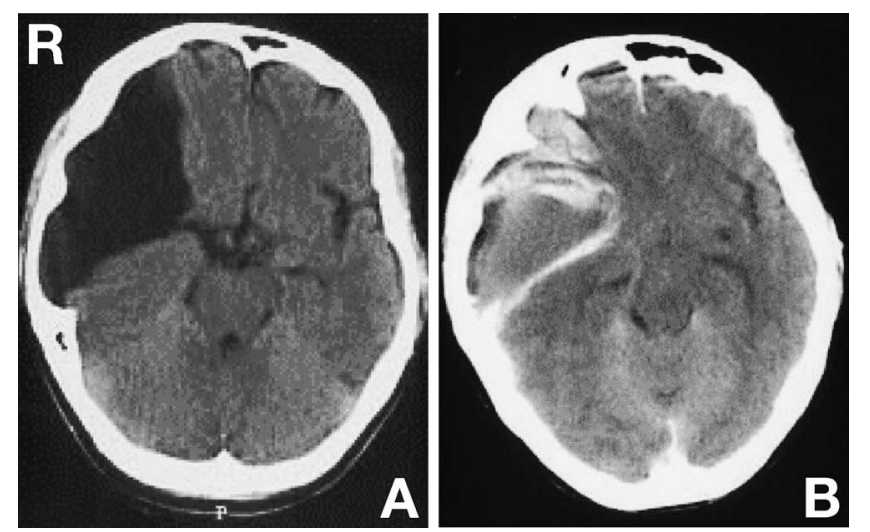

Fig. 1 Computed tomography scans, (A) initially showing no hematoma in the arachnoid cyst of the right middle fossa, and (B) revealing intracystic hematoma of the arachnoid cyst with uncal herniation 3 weeks later.
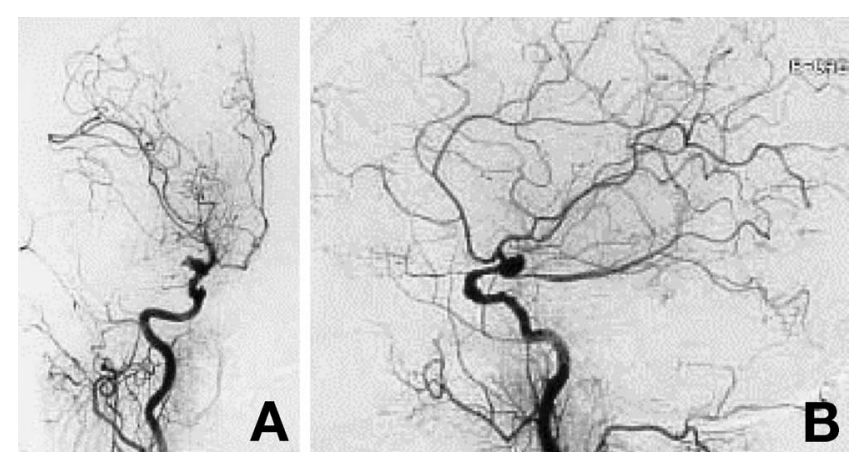

Fig. 2 Right carotid angiograms, (A) anteroposterior and (B) lateral views, demonstrating a right internal carotid-posterior communicating artery aneurysm. artery and complete aneurysm neck clipping were confirmed by intraoperative ultrasonography using a micro-Doppler probe. The residual intracystic hematoma was evacuated following aneurysm clipping. Empty middle fossa was also observed.

The patient recovered consciousness soon after the operation. Postoperative angiography revealed complete neck clipping and no evidence of vasospasm. Left hemiparesis was persistent, and the patient was discharged 1 month later.

\section{Discussion}

Intracystic hematoma of the arachnoid cyst originating from ruptured aneurysm is extremely rare..$^{2-6,9,10)}$ Only eight cases have been reported including the present case (Table 1). Lesions were located on the left in six cases. Ruptured aneurysms arose from the internal carotid-posterior communicating artery and middle cerebral artery, which are located adjacent to the middle cranial fossa. Usually, rupture of intracranial aneurysms results in subarachnoid hemorrhage. Recurrent hemorrhage may cause dissection into the cerebral parenchyma and bleeding into the subdural space. ${ }^{3,5)}$

In previous cases, the ruptured aneurysm adhered to the arachnoid membrane, and so may have bled directly into the arachnoid cyst and subdural space through a local tear in the arachnoid membrane resulting from increased intravascular pressure and leading to decompressing rupture. However, no such episode of intracranial hemorrhage occurred in the present case. Initial CT revealed typical arachnoid cyst in the middle cranial fossa without hemorrhage or mass effect after the patient suffered sudden onset of severe headache. Retrospectively, this should have been considered as a warning sign

Table 1 Intracystic hematoma of the arachnoid cyst caused by ruptured aneurysm

\begin{tabular}{|c|c|c|c|c|c|c|c|c|}
\hline Author (Year) & $\begin{array}{l}\text { Age } \\
\text { (yrs) }\end{array}$ & Sex & Location of arachnoid cyst & $\begin{array}{l}\text { Location of } \\
\text { aneurysm }\end{array}$ & $\begin{array}{l}\text { Distribution of } \\
\text { hematoma }\end{array}$ & $\begin{array}{l}\text { Diffuse } \\
\text { SAH }\end{array}$ & $\begin{array}{c}\text { Interval } \\
\text { between } \\
\text { intracystic } \\
\text { hematoma and } \\
\text { aneurysm } \\
\text { (days) }\end{array}$ & Outcome \\
\hline Jinkins et al. $(1987)^{6)}$ & 40 & $\mathrm{M}$ & rt sylvian fissure-middle fossa & rt MCA & intracystic and SAH & - & 4 & GR \\
\hline Shimazu et al. $(1990)^{9)}$ & 51 & $\mathrm{~F}$ & lt sylvian fissure-middle fossa & lt MCA & intracystic and SAH & - & 1 & GR \\
\hline Hirose et al. (1995) $)^{4)}$ & 45 & $\mathrm{M}$ & lt sylvian fissure-middle fossa & lt IC bifurcation & intracystic & - & 3 & GR \\
\hline Barker et al. (1998)²) & 29 & $\mathrm{~F}$ & lt sylvian fissure-middle fossa & lt IC-PC & $\begin{array}{l}\text { intracystic and SAH } \\
\text { and hydrocephalus }\end{array}$ & - & 7 & GR \\
\hline Huang et al. (1999)5) & 61 & $\mathrm{~F}$ & lt sylvian fissure-middle fossa & lt MCA & intracystic and SDH & - & 2 & GR \\
\hline Zanini et al. $(2000)^{10)}$ & 35 & $\mathrm{M}$ & lt sylvian fissure-middle fossa & lt IC bifurcation & intracystic and SAH & - & 1 & GR \\
\hline Berhouma et al. $(2006)^{3)}$ & 37 & $\mathrm{~F}$ & lt sylvian fissure-middle fossa & lt MCA & intracystic and SDH & - & 1 & GR \\
\hline Present case & 46 & $\mathrm{~F}$ & rt sylvian fissure-middle fossa & rt IC-PC & intracystic & - & 20 & SD \\
\hline
\end{tabular}

GR: good recovery, IC: internal carotid artery, IC-PC: internal carotid-posterior communicating artery, MCA: middle cerebral artery, SAH: subarachnoid hemorrhage, SD: severe disability, SDH: subdural hematoma. 
of aneurysm rupture. The clinical course was uneventful, and the symptoms improved spontaneously. Intracranial hemorrhage was detected 3 weeks after the initial onset. Subsequent angiography revealed the ruptured aneurysm. Consequently, the diagnosis of aneurysm was delayed in the present case.

The diagnosis of the coexisting ruptured aneurysm was delayed in five of the eight cases of intracystic hematoma ${ }^{2,4-6)}$ (Table 1). Such cases of aneurysm rupturing directly into the arachnoid cyst cavity resulting only in intracystic hematoma without definite subarachnoid hemorrhage are difficult to identify. In addition, no vasospasm occurred in any patient. Therefore, the clinical outcome was generally favorable. However, in the present case, the delayed diagnosis allowed rerupture of the aneurysm resulting in increasing pressure and mass effect of the arachnoid cyst caused by the huge hematoma, which is similar to the pathogenesis of acute subdural hematoma.

The present case shows that we should consider the possibility of coexistence of arachnoid cyst and ruptured aneurysm, indicating that cerebral angiography is required to investigate intracystic hematoma of the arachnoid cyst, especially in the absence of head injury.

\section{References}

1) Auer LM, Gallhofer B, Ladurner G, Sager WD, Heppner F, Lachner H: Diagnosis and treatment of middle fossa arachnoid cysts and subdural hematoma. J Neurosurg 54: 366-369, 1981

2) Barker RA, Phillips RR, Moseley IF, Taylor WJ, Kitchen ND, Scadding JW: Posterior communicating artery aneurysm presenting with haemorrhage into an arachnoid cyst. J Neurol Neurosurg Psychiatry 64: 558-560, 1998

3) Berhouma M, Jemel H, Khaldi M: Aneurysm rupture into an arachnoid cyst of the middle cranial fossa. $J$ Neuroradiol 33: 206-208, 2006

4) Hirose S, Shimada S, Yamaguchi N, Hosotani K, Kawano H, Kubota T: Ruptured aneurysm associated with arachnoid cyst: Intracystic hematoma without subarachnoid hemorrhage. Surg Neurol 43: 353-356, 1995

5) Huang D, Abe T, Kojima K, Tanaka N, Watanabe M, Ohkura A, Nishimura H, Hayabuchi N, Norbash AM: Intracystic hemorrhage of the middle fossa arachnoid cyst and subdural hematoma caused by ruptured middle cerebral artery aneurysm. AJNR Am J Neuroradiol 20: 1284-1286, 1999

6) Jinkins JR, Siqueira EB, Holoubi A: Ruptured middle cerebral aneurysm with accumulation of subarachnoid blood within convexity arachnoid cyst. Comput Radiol 11: 185-187, 1987

7) Mori T, Fujimoto M, Sakae K, Sakakibara T, Shin H, Yamaki T, Ueda S: Disappearance of arachnoid cyst after head injury. Neurosurgery 36: 938-942, 1995

8) Ochi M, Morikawa M, Ogino A, Nagaoki K, Hayashi K: Supratentorial arachnoid cyst and associated subdural hematoma: neuroradiologic studies. Eur Radiol 6: 640-644, 1996

9) Shimazu M, Homma M, Kaji M, Abe T, Tanaka H, Nemoto S, Kiyota K, Sakamoto T, Ariga T: [A case of ruptured aneurysm associated with arachnoid cyst]. Nihon Kyukyu Igakkai Zasshi Kantoshi 11: 684-686, 1990 (Jpn)

10) Zanini MA, Gabarra RC, Faleiros AT, Freitas CC, Alves A: [Cerebral aneurysm and arachnoid cyst: about a case with intracystic hemorrhage]. Arq Neuropsiquiatr 58(2A): 330-335, 2000 (Por, with Eng abstract)

Address reprint requests to: Toshihide Tanaka, M.D., Department of Neurosurgery, Jikei University School of Medicine, Kashiwa Hospital, 163-1 Kashiwashita, Kashiwa, Chiba 277-8567, Japan.

e-mail: ttanaka@jikei.ac.jp 